In this paper, three examples of existing types of livestock production from three different countries will be analysed, compared and discussed in relation to the organic principles health, ecology, fairness and care. The potential and relevant directions for future development will be discussed based on this analysis. The three cases are:

(1) the case of mixed Cuban livestock farming, typically involving pigs, cattle and poultry in an agro-forestry system or rotational grazing/ fodder bank system. In the Cuban case the transition to agro-ecological system has been necessary from the early 1990s and integrated diverse systems exist, as well as a number of remaining challenges, which need to be solved,

(2) the case of Ugandan organic smallholder farms with dairy cows and possibly also small ruminants and/or poultry. In Uganda, organic farming has been growing rapidly over the last decade, to a large extent in terms of crop, fruit and vegetable production for export in certified organic systems. Here the challenges are related to integrating livestock into these systems and live up to the organic principles within the livestock sector,

(3) West Bengal integrated fish and farming systems with poultry and small ruminants (goats/sheep). The specific area taken is the Sunderbans area, which is a vulnerable eco-system and an overpopulated area. Extensive amounts of pesticides have previously been promoted, and livestock systems tend to be unbalanced in terms of nutrition cycles and land use, and where fish have largely died out because of seeding-harvest for export. This is a case of organic/agro-ecological approach being adopted for agricultural rehabilitation.

When discussing the cases, we consider various organic approaches to breeding, use of indigenous breeds, availability of outdoor access and the potential for animals to improve agriculture in the specific regions. We shall also consider the potential conflicts in achieving the multiple objectives of organic production.

In organic livestock systems, feeding should always be species-specific and as far as possible local and home-grown. This fits well into the integrated and diverse systems, although some dilemmas exist, such as meeting the protein requirements of mono-gastric animals and the potential conflict this presents with regard to human food production and needs as well as in relation to environmental issues. Although emphasis is on animal disease prevention and health promotion, an anomaly within organic legislation is the allowance of chemicals in veterinary medicine, whereas agro-chemicals are prohibited in all areas of the crop production. We will therefore also discuss the role of vaccination, traditional medicine and alternatives to biomedical treatments and other approaches to disease management under the specific conditions of the case-study areas e.g. control of vector-borne diseases in Uganda.

\title{
Level of assessment of livestock farming systems: farm, sector, and territory
}

\author{
Javier Mata ${ }^{1}$, Luis Alberto Bermejo Asensio ${ }^{1}$ and Patrick Caron $^{2 \dagger}$ \\ ${ }^{1}$ Univ. de La Laguna, Spain; ${ }^{2}$ CIRAD, France
}

Livestock production is currently facing new challenges, among which are two major ones. The first one relates to the trade off between the need for an increasing production in relationship with an increasing income in fast growing economies and demographic patterns (9 billion people in 2050) and the call for a decreasing per capita consumption in OECD countries for health reasons. The second one is the need to consider environmental concerns when looking at livestock production patterns and stimulating innovation; this relates not only to "traditional" pollution responsibility but also to the mitigation of climate change.

This calls for renewing the criteria of assessment of production and productivity. Livestock production should not only be evaluated through the volume of marketable products, such as meat, milk, eggs, etc, but also through the impact in terms of employment, greenhouse gas emission, water quality, etc. There is indeed a need for reviewing the concept of performance and the methods of its assessment. The challenge is made difficult if one considers that such an assessment should make it possible to address trade offs between the different functions of livestock production on the one hand and between levels of organization on the other hand. A dynamic could be positive at the farm level and negative at the territory level, or inversely.

After identifying these challenges, the authors will provide a quick inventory of the classical methods to assess livestock farming systems at the farm, commodity and territory levels. They will pay more attention to recent advances and examples, in particular at the territory level, through methodological approaches to understand the regional evolution of livestock systems based on the analysis of farmers' practices. The identification and interpretation of changing situations highlight the need for an explicit analysis of local, as well as global, phenomena and for an integration of different time scales. To do so, special attention can be paid to the territorial management practices of livestock systems. Such an orientation aims at taking into account the influence of space and integrating different spatial scales that are meaningful vis-à-vis changing situations.

\footnotetext{
† E-mail: patrick.caron@cirad.fr
} 
Finally, the authors conclude with the need of designing new conceptual and methodological frameworks in order to address the tradeoffs between farms, sectors and territorial outputs and assessments. Such a requirement is made even more urgent when looking at time and considering flexibility and resilience in a changing context as key elements of sustainability.

\title{
Representations of breeders about local breeds in the livestock farming system of the French West Indies: between rejection and appropriation of Creole goat
}

\author{
V. Angeon ${ }^{1 \dagger}$, J. Sainton ${ }^{2}$ and G. Alexandre ${ }^{3}$ \\ ${ }^{1}$ Université Antilles Guyane CEREGMIA, Martinique; ${ }^{2}$ Institut Universitaire de Formation des Maitres, CRREF, Guadeloupe; ${ }^{3}$ INRA UR 143 UR Zootechniques, Antilles-Guyane
}

\section{Introduction}

The institutionalisation of sustainable development is a turning point in the evolution of public policies. The latter are marked by major new aspects such as, the acknowledgement of a regional local scale, necessary for the implementation of decision-making and public action, within the framework of a harmonious development in which the citizen plays an active part. The valorisation of local resources is also part of that new scheme, for it takes into account, the perspective of environmental as well as economic and social aims. The promotion of sustainable agriculture, as well as that of local breeds (LB), is encouraged, within that framework. Such a plan is in accordance with actions for the preservation of biodiversity at international scales, (FAO, DAD). Such is also the case in the French West Indies. The latter areas, now under urban influence, lead us to reconsider the importance and the role of a sector, historically dominant but now threatened. As an example, the accumulation of scientific knowledge about the Creole goats of the FWI tends to demonstrate their positive points and advantages in the livestock farming system (LFS, Alexandre et al., 2009). They are adapted to the physical environment of isolated tropical areas and are known to be more adapted to climate conditions, pasture resources, and diseases. From a scientific point of view, the Creole goats are in a better position to contribute to the sustainability of the local LFS: when husbandry conditions are based on low externalities their performances reach adequate levels. In spite of the advantages recognized in this Creole breed, the practices of the breeders in the FWI (uncontrolled introduction of exotic genotypes), do not allow its potentaill development (Alexandre and Angeon, 2010) and sometimes lead to its rejection.

What are the representations of the breeders in the French West Indies about the LB? Several works develop the idea that the norms and values within a system preside over action (Argyris and Schön, 1996) and that all changes in practices relate to the evolution of references.

\section{Conditions of rejection and appropriation}

The object of this text is to come to an understanding of the sequence composed of - representations, appropriation, and practices - within the context of animal farming system in the FWI. In those societies, human values are taken into account, for they interact with productive patterns. This study allows analysis of the level of representation of agents and to make explicit the mechanisms and processes subsequent to their evolution. The hypothesis that was first established in a previous work (Alexandre and Angeon, 2010) is demonstrated throughout this text. It stipulates that the dynamics of those representations are all the more plausible as it lies within a collective framework, which facilitates the appropriation and the learning of new practices. As such the work tends to determine the factors of emergence of those collective frameworks in the FWI.

In the present study the following causes, leading to the rejection of local breeds in the FWI context, have been identified in terms of human values. First and foremost, we may consider, as it has been said by Bernabé et al. (1989),that societies have an external and exotic view of themselves. Therefore, they are likely to develop a strong repulsion against their own practices and patrimony (traditional LFS and local breeds), once the latter have been made formal by the researcher, when an official economy is developed. Second, the French West Indian Man acts according to long decayed economic patterns- the plantation system. Trapped in this old-fashioned pattern (Crusol, 2007), man may unconsciously show strong resistance against an internally oriented system of production. Last but not least, the term "Creole", which enjoys high reputation for its identity, is also equivalent of a "compromise", with a difficult Past and therefore is not successful when linked to production.

\section{Conclusion}

These three factors, fundamental constituents of contemporary French West Indian societies, may be helpful to understand the rejection/ appropriation dialog faced over local breeds. In order to implement adapted LFS, the authors recommend actions aiming at decision makers, researchers, teachers and extension officers likely to induce a sequence composed of - representations, appropriation, and practices.

${ }^{\dagger}$ E-mail: valerie.angeon@martinique.univ-ag.fr 